\title{
Las políticas migratorias en España desde la prensa colombiana, 1990-1999: entre la integración europea y la integración iberoamericana*
}

\section{Victoria Bazurto**}

\section{RESUMEN}

Frente a la idea de integración que se vive en la década de los noventa, se antepone igualmente la de protección de las fronteras que se pondrá en marcha con los acuerdos europeos de libre circulación. Frente a ello, las relaciones políticas que se establecen entre los diferentes países de Iberoamérica, se verán modificadas al constatar, según los resultados obtenidos del análisis minucioso realizado a la prensa colombiana, el desequilibrio no solamente en el trato-desde el punto de vista económico- entre Europa y América Latina, sino también, discriminatorio frente a los migrantes originarios de esta zona que ya empezaban a migrar hacia España.

Palabras clave: migración colombiana, políticas migratorias europeas, relaciones internacionales, iberoamericanismo.

* Este artículo forma parte de la investigación correspondiente a la tesis doctoral titulada "Imagen(es) y representación(es) de la migración colombiana a Espańa: estudio comparado de la prensa colombiana y la prensa española 1990-2006", inscrita en la Universidad de Nantes (Francia), bajo la dirección de la doctora Pilar MartínezVasseur, en cotutela con la Universidad Externado de Colombia, bajo la dirección de la doctora Milena Gómez Kopp.

** Magíster en Estudios Culturales de la Universidad de Nantes, Nantes (Francia). vickybazurto@gmail.com Recibido: 3 de abril de 2015 / Modificado: 7 de mayo de 2015 / Aceptado: 9 de junio de 2015.

Para citar este artículo

Bazurto, V. (2015). Las políticas migratorias en España desde la prensa colombiana 1990-1999: entre la integración europea y la integración iberoamericana. OASIs, 21, 29-53. DOI: http://dx.doi.org/10.18601/16577558.n21.03 
The migratory policies in Spain from the perspective of the Colombian press, 1990-1999: Between the European integration and Ibero-American integration.

\section{ABSTRACT}

Facing the current nineties' idea of integration is the idea of border protection that will be launched with the European free movement of persons treaties. According to the thorough analysis done by the Colombian press, the political relations that are established amongst the various Ibero-American countries will be modified once they verify the imbalance, not only in the economical treatment between Europe and Latin America, but also the discriminatory treatment toward the migrants originating from this zone that have already started to migrate to Spain.

Key words: Colombian migration, migratory policies, international relationships, Ibero-Americanism.

\section{INTRODUCCIÓN}

Las fechas en las que se inserta este artículo ${ }^{1}$, fuera de ser la década marcada por los diferentes procesos de integración política y económica que se viven en el mundo (Urquidi y Vega, 1991) $)^{2}$, corresponden para España, a una época de consolidación de un país que pasa de ser emisor a ser receptor de migrantes, que igualmente se perfila como motor importante en la escena internacional; para Colombia, representan la internacionalización de su economía, así como la reestructuración del Estado bajo una nueva Constitución, y el inicio del segundo ciclo migratorio más grande que conocerá el país a finales de la década.

En este contexto, al tratar de determinar la visión que transmiten los periódicos colombianos El Tiempo y El Espectador, sobre la migración colombiana hacia España, pudimos constatar que sus notas no se dirigen tanto a retratar la emigración y al emigrante, sino que dedicarán gran parte de ellas a seguir de cerca la integración europea y las políticas migratorias que propone. Lo anterior, a la luz del proceso de integración iberoamericana que se presenta,

1 Si bien la literatura consultada sobre la migración colombiana hacia España, coincide en que este flujo se inicia a finales de la década de los noventa, nos parecía importante analizar todo el periodo desde el 1 de enero de 1990 hasta el 31 de diciembre de 1999, con el fin de determinar los puntos importantes que surgen como referentes con respecto al tema en la prensa (entre ellos las políticas migratorias), antes de que el fenómeno tomara fuerza a partir del 2000 , año en el que se inicia la segunda parte del estudio hasta el 31 de diciembre de 2006. Esto con el fin de realizar un seguimiento detallado de la presencia o emergencia de este fenómeno social en el discurso creado por los periódicos seleccionados, y así poder establecer una línea de análisis y comparación, que sirva para identificar de dónde surge y cómo se construye la imagen y la representación de los migrantes colombianos en la totalidad del periodo.

2 En este libro se reúnen tanto los discursos como las ponencias de diferentes responsables mundiales, economistas y académicos, en torno a la integración mundial, y a lo que ello podría aportar en la posible construcción de un modelo de integración para América Latina. 
desde el punto de vista de la política migratoria, como incompatible con la integración española en la Unión Europea.

\section{LA INTEGRACIÓN IBEROAMERICANA Y LAS RELACIONES BILATERALES ESPAÑA-COLOMBIA}

En el caso de España, el final de los años ochenta concluye con la entrada de este país a la entonces Comunidad Económica Europea (CEE), después de la firma del Acuerdo de Adhesión en 1986, y su ingreso en la Organización del Tratado del Atlántico Norte (OTAN). De esta manera, y a lo largo de la década de los noventa, liderada en gran parte por los diferentes Gobiernos del Partido Socialista Obrero Español (PSOE) de Felipe González (1982-1996), Espańa rompe de manera definitiva su aislamiento internacional, e inicia la creación y posterior consolidación de una política exterior que le abra un lugar en la escena mundial (Del Arenal, 2011).

América Latina, en medio de esa política exterior del psOE, no necesariamente es uno de los frentes importantes, como lo serán los países europeos o Estados Unidos; sin embargo, y tal como ha sido a lo largo del siglo xx, será un área sensible por razones de tipo político, histórico y cultural (Delgado y Escolanilla, 2003, p. 125). Prueba de ello, son los anexos que quedaron estipulados al momento de firmar el Acuerdo de Adhesión a la CEE, en los que Espańa exige de la CEE una atención particular hacia América, debido a los lazos que unen a este país y a Portugal (Del Arenal, 1992, p. $205)^{3}$, igualmente, con la región.

Cabe resaltar que si bien la política exterior española incluye a América Latina, el acercamiento entre la península y América se verá supeditado, al menos hasta finales de los años ochenta y principios de los noventa, al hecho de que antes de pensar en una organización Iberoamericana, había que resolver otros asuntos de vital importancia para el Gobierno espańol, como lo eran sus relaciones de vecindad con Francia y con Marruecos, y, evidentemente, su entrada a la CEE. Por otro lado, había que establecer sobre nuevas bases las relaciones con la región, diferenciándose de la política hispanoamericanista del franquismo, o aún de la desarrollada por los gobiernos de la transición, puesta en práctica por el Partido Unión de Centro Democrático (UCD) ${ }^{4}$.

3 Portugal firma el Acuerdo de Adhesión a la ceE en 1986, igual que España. Por otro lado, a pesar de las dificultades, España consiguió que la especial relación con Iberoamérica se plasmara en las declaraciones anexas al Tratado y al Acta de Adhesión, firmados el 12 de junio de 1985: "la Declaración Común de Intenciones relativa al desarrollo y a la intensificación de las relaciones con los países de América Latina, común a los diez Estados miembros de las Comunidades europeas, a Espańa y a Portugal, y la Declaración del Reino de España sobre América Latina; la gestión da origen a la adopción, en 1987, del documento: 'Nuevas Orientaciones de la Comunidad europea para las relaciones con América Latina', adolecen de un importante desequilibrio en el tratamiento de los aspectos políticos respecto a los económicos” (Del Arenal, 1992, p. 206).

4 "La política iberoamericana, con todo lo que tenía de retórica e imagen, en ocasiones se usó como una política de 'sustitución', al estilo de la franquista, aunque con distinto acento, que tendía a llenar el eventual vacío que se podía 
La política exterior española queda entonces configurada a finales de la primera legislatura del PSOE (1982-1986) y sentará las bases de lo que será hasta finales de su Gobierno en 1996 y, de cierta manera, el primer Gobierno de José María Aznar (1996-2000) (Del Arenal, 2011, p. 113). Hay que destacar que en la tarea de reformular y reorientar la política iberoamericana de España, le correspondió un papel importante, en cuanto definidor de una política de Estado, al rey de España, Juan Carlos I, tal como lo contempla la Constitución de 1978 en su artículo 56.1, a través del cual el rey es "el Jefe del Estado, símbolo de su unidad y permanencia [...] asume la más alta representación del Estado español en sus relaciones internacionales, especialmente con las naciones de comunidad histórica" (Constitución Española, art. 56.1).

En este sentido, el que fuese el rey el encargado de las relaciones, dará estabilidad desde el punto de vista de la imagen de América hacia España, ya que se considera como una política de Estado, señalada por la Constitución Espańola, y no una política gubernamental, sujeta a cambios en función de los partidos que ocupen la dirección del gobierno.

Esta política justamente se tradujo, a partir de 1985, en la creación de la Secretaría de Estado para la Cooperación Internacional y para Iberoamérica (SECIPI), así como de los tratados de cooperación y amistad que se suscribieron con los diferentes países latinoamericanos a partir de la época, que en lo que concierne a Colombia fue firmado en el año 1992.

Es justamente a principios de la década, que el deseo de ver el surgimiento de una Comunidad Iberoamericana de Naciones va a materializarse. Comunidad esta, que en lugar de modelos, pretendía aportar experiencia política y técnica para impulsar el pluralismo democrático y el despliegue económico (Delgado y Escolanilla, 2003, p. 151). En consonancia con estos principios, las acciones del Gobierno español se centran en su apoyo a los procesos de democratización de los países centroamericanos, como Nicaragua y El Salvador, así como posteriormente apoyó los procesos de transición de países del cono sur hacia la democracia. Tal fue el caso de Chile, Argentina, Uruguay y Paraguay, o los procesos de negociación del Gobierno colombiano con las diferentes guerrillas en los años ochenta, $y$ los que existieron entre los gobiernos sucesivos a lo largo de la época, como fue la negociación entre el gobierno de Andrés Pastrana con las Fuerzas Armadas Revolucionarias de Colombia (FARC) entre 1998-2002 (Delgado y Escolanilla, 2003, pp. 152-153).

Por otro lado, se fortalecían otros espacios de diálogo creados desde los años ochenta como los Encuentros en la Democracia, patro-

producir en la afirmación de la dimensión europea de Espańa, mediante la apertura de una tercera vía. Otras veces se utilizó como una política de 'presión', dirigida a reforzar la posición negociadora de Espańa frente a la Comunidad Europea y a Estados Unidos. Finalmente, se usó como política de 'legitimación' de la propia Unión de Centro Democrático a nivel interno, buscando a través de un pretendido 'progresismo' lavar la herencia franquista que caracterizaba a una parte significativa de sus miembros” (Del Arenal, 1992, p. 174). 
cinados por el Instituto de Cooperación Iberoamericana, a través de los cuales se buscaba "fomentar los contactos entre representantes de la política, la cultura, la economía, la ciencia y la sociedad" 5 , así como las reuniones periódicas que tuvo la Conferencia Iberoamericana de Comisiones Nacionales para la Conmemoración del V Centenario, encaminadas a la preparación de este evento.

Un paso importante en la consolidación de las relaciones entre estas naciones, será la I Cumbre Iberoamericana de Jefes de Estado y de Gobierno, que tuvo lugar en Guadalajara (México) en 1991, punto de inicio de las cumbres que se llevarán a cabo desde entonces. El hecho más relevante de esta cumbre, es que con ella se marca "el paso de una comunidad de facto a una comunidad de iure alcanzando con ello, la visibilidad y la presencia política externa que corresponde a los cambios y a la modernización emprendidos por las naciones iberoamericanas en la década" (De la Riva, 1992, pp. 168-187).

Como resultado de este proceso político de unificación dinamizado por la celebración del v Centenario del Descubrimiento de América en Madrid en 1992, surgen otras iniciativas y proyectos de ciencia, tecnología, cultura y comunicaciones, sin olvidar la educación. En este sentido, el Gobierno español otorgó becas a estudiantes latinoamericanos que entre 1980 y 1991 ascendieron a 9714, se creó el Programa de Becas Mutis de Cooperación Universitaria y de Movilidad de Posgraduados, entre otros (Delgado, 2003, p. 156).

De manera paralela, se crearon los diferentes dispositivos necesarios para coordinar la política de cooperación que se venía desarrollando. Entre ellos, la Secretaría de Estado para la Cooperación Internacional y para Iberoamérica (SECIPI) (1985), la Comisión Interministerial de Cooperación Internacional, responsable desde entonces de la elaboración del Plan Anual de Cooperación Internacional (PACI) (1986) etc. $^{6}$ La puesta en marcha de estas entidades, se acompañó de un presupuesto importante que entre 1982 y 1992 se multiplicó por cuatro, en lo que concierne a la ayuda multisectorial que Espańa destinaba para América Latina, es decir, que el $80 \%$ de los fondos para cooperación exterior se destinaron a la región, de la misma manera que lo hicieron los capitales privados espańoles (Ramiro et al., 2008, pp. 21-26).

En lo que se refiere a las relaciones bilaterales con Colombia, puede decirse que la política entre los dos países ha seguido la misma tendencia, a saber: que si bien para Espańa, la región no ha sido una prioridad, para Colombia tampoco lo era Espańa, y su política se

\footnotetext{
5 Iberoamérica. Encuentro en la Democracia, Madrid, Instituto de Cooperación Iberoamericana, 1983, y Encuentro en la Democracia Europa-Iberoamérica, Madrid, Instituto de Cooperación Iberoamericana, 1986 (citado en Delgado, 2003, p. 153).

6 "Organismos que se modificaron en 1988, dando origen a la Agencia Española de Cooperación Internacional como organismo autónomo de la Administración del Estado, adscrito al Ministerio de Asuntos Exteriores, en cuyo seno se integraban el Instituto de Cooperación Iberoamericana y la Comisión Nacional para la Conmemoración del Quinto Centenario” (Delgado y Escolanilla, 2003, p. 154).
} 
dirigía principalmente hacia Estados Unidos (Rodríguez, 2006, p. 144). Esto a pesar de los acuerdos de cooperación para el desarrollo que venían funcionando desde la década de los ochenta (p. 149). El punto de inflexión llega en 1992, con la firma del Tratado General de Cooperación y Amistad, firmado por los presidentes César Gaviria y Felipe González ${ }^{7}$. Cabe resaltar que las relaciones se van estrechando a lo largo de la época, con la llegada del PP al gobierno espańol a partir de 1996, época en que las administraciones de los presidentes colombianos Andrés Pastrana (1998-2002) y posteriormente Álvaro Uribe (2002-2010), en conjunto con el presidente José María Aznar (1996-2004), dieron un importante empuje, fortaleciendo los vínculos en los sectores político, económico, de defensa y de cooperación (Oxfam, 2010, p. 7).

En términos económicos, la entrada de España a la CCE supuso, con respecto a América Latina, una disminución de las exportaciones e importaciones espańolas; igual sucedió en el caso colombiano, las primeras pasaron entre 1985 y 1993 del 5,8 al 5,6\%, y las segundas de 11,4 a 4,4\%. En contrapartida, la inversión extranjera directa (IED) aumentó (Delgado, 2003, p. 158). Esto se tradujo en una fuerte presencia de empresas españolas en la región, que llevaron a España a ser el "sexto país inversor del mundo en 1999, año en que precisamente concentró el $66 \%$ de sus inversiones extranjeras en América Latina" (Ramiro et al.,
2008, p. 26). Esta estrategia económica, denominada por Javier Noya como la estrategia del " 4 veces 7", se desarrolló en 7 años, entre 1993 y 1999, en 7 países -Argentina, Brasil, Chile, México, Colombia, Perú y Venezuela-, en 7 sectores -petróleo, gas energía eléctrica, banca, telecomunicaciones, seguros y medios de comunicación-, desde 7 empresas españolas -BBVA, Banco Santander, Repsol, Gas Natural, Endesa, Iberdrola y Unión Fenosa-, y Prisa, que en este caso sería una octava (Noya, 2009, p. 316). Esta situación, por un lado, asegura una fuerte presencia de Espańa en la región, y por el otro, debido al corto tiempo en el que se realizó y los sectores en los que se implantó, es decir, sectores privatizados por los Estados americanos, generó algunas reacciones de malestar y de rechazo llevando a calificarla como un hecho de "reconquista" o "recolonización" (p. 317). En el caso de Colombia, "entre 1992 y 2001, Espańa aportó el $40 \%$ del total de los 6.600 millones de euros de IED que invirtió la UE más EE.UU." (Ramiro et al., 2008, p. 73). Por otro lado, dentro de los sectores en los que se implantan las multinacionales españolas en este país, se encuentran el de la construcción (ACS, ferrovial), el sector de aguas (AGBAR, Canal Isabel II y FCC); el sector financiero (BBVA, Santander) el de hidrocarburos (CEPSA, REPSOL YPF), la electricidad (ENDESA y Unión Fenosa), el gas (Gas Natural), y otras empresas en sectores como las comunicaciones (Grupo PRISA), entre otras que se instalaron en los servicios de la sanidad (Colsanitas), de los seguros (Map-

Jefatura de Estado, Tratado general de cooperación y amistad entre el Reino de Espańa y la República de Colombia, 1995, Boletín Oficial del Estado (воE), núm.182. Disponible en: https://www.boe.es/diario_boe/txt.php?id=BOEA-1995-18484 
fre) o de la seguridad (Prosegur) (Ramiro et al., 2008).

Para finales de la década, la presencia de Espańa y las relaciones tanto con la región como con Colombia, quedan configuradas a través de los diferentes acuerdos políticos y de cooperación firmados, la intervención de España en diferentes procesos de democratización en el continente, así como su intervención en la UE a favor de potencializar los acuerdos con la región. Asimismo, es innegable que a finales de la década, España se ve representada en América Latina a través del rol que tendrán las relaciones comerciales y de IED que se consolidan, al punto de llegar a hacer de este país el segundo inversor en la región después de EE.uU.

\section{LA INTEGRACIÓN EUROPEA Y LAS POLÍTICAS MIGRATORIAS}

Los movimientos de población que se dirigen hacia España, originarios de la región, que para finales del siglo $\mathrm{xx}$ representaban el $21 \%$ de la población extranjera en España (Izquierdo y Fernández, 2006, p. 444), suponen un "elemento de primera magnitud para el rumbo que [tomarán] las relaciones" (Delgado, 2003, p. 159) en lo consiguiente. Teniendo en cuenta que tanto su control como su regulación, no dependen únicamente de la política espańola, sino también, y en gran medida, de los acuerdos que se firman entre los países miembros de la reciente, para entonces, UE.

En la década de los noventa, tienen lugar varios momentos importantes en materia de integración europea que, por ende, conciernen de manera directa a España, y que están rela- cionados con la política migratoria aplicada en el espacio europeo, lo que de por sí concierne a los países latinoamericanos, cuyos ciudadanos ya comenzaban a migrar hacia España. No hay que dejar de lado que para la época, se había firmado el Acuerdo de Schengen (1985), que tiene por objeto la eliminación progresiva de los controles en las fronteras comunes y establecer el régimen de circulación para los nacionales de los Estados signatarios, desarrollado en 1990 por el Convenio de aplicación que definirá las condiciones y las garantías de la libre circulación.

A principios de los años noventa, en 1992, se firma el Tratado de Maastricht o de la Unión Europea, que determina la creación de la UE, antes CEE, como entidad política, a su vez que define las instituciones que le rigen: Consejo Europeo, Consejo de Ministros y el Parlamento. Con este acuerdo se fijan igualmente los objetivos de la Unión, entre ellos, la ciudadanía europea; el mercado único; la integración monetaria y económica; la política exterior y de seguridad común, y la cooperación judicial y policial. En esta última se incluyen las áreas del derecho penal y civil, la lucha contra el crimen organizado, y las políticas de inmigración, asilo y circulación de personas (García et al., 2008, pp. 157-158). Seguido a este, el Tratado de Amsterdam, en 1997, sitúa la política migratoria en el marco de Espacio de Libertad, de Seguridad y de Justicia, suscribiéndola a un enfoque principalmente de defensa de las fronteras y de fuertes restricciones a la entrada de terceros países (Actis et al., 1999, p. 151). Finalmente, la reunión de jefes de Estado y de Gobierno en Tampere, en octubre de 1999, da un paso decisivo en materia migratoria ya 
que se fija como objetivo el "dotar a la UE de una política común en materia de asilo y de inmigración, teniendo en cuenta la necesidad de ejercer en las fronteras exteriores un control coherente, con el fin de parar la inmigración clandestina" (Berramdane y Rosseto, 2009, p. 45). Para llevar a cabo este cometido, se delimita la política europea en cuatro objetivos entre los que se encuentran, crear acuerdos con los países de origen y tránsito de la inmigración, un régimen de asilo común, un trato igualitario para los residentes de los terceros países y la gestión eficaz de los flujos migratorios ${ }^{8}$.

Sin embargo, el que la política europea haya situado la inmigración en el marco de la política de libertad, seguridad y justicia, significó desde el punto de vista de la normativa, un acercamiento entre la inmigración y la seguridad. En este sentido, se desarrolla así una

...obsesión securitaria en la que han quedado enmarcadas [estas] que en ocasiones amenazan con propiciar la falacia de identidad entre flujos migratorios y riesgo terrorista, lo que justifica la adopción de medidas restrictivas en el reconocimiento y garantía de los derechos de los inmigrantes y la $[\ldots]$ asociación de dichos países en las funciones de policía de fronteras, presididas por la misma lógica (De Lucas, 2003, p. 54).

Estos cambios son importantes para lo que serán los acuerdos establecidos entre los diferentes países latinoamericanos que conciernen a la migración y España.

\section{EL TEMA DE LAS POLÍTICAS MIGRATORIAS EN LOS PERIÓDICOS COLOMBIANOS EL TIEMPO Y EL ESPECTADOR 1990-1999}

Las noticias relacionadas con la comunidad colombiana en España, son prácticamente minoritarias en los periódicos colombianos durante la época de los noventa, tal como se observa en la figura 1. Espańa aparece junto a países como Ecuador, Estados Unidos y Venezuela, que forman parte de los destinos migratorios de la comunidad desde el primer gran periodo de la migración colombiana en los años setenta (Arbeláez, 1977; Mármora, 1979). 
FIGURA 1

RESULTADO DE LOS ARTÍCULOS POR AÑO Y POR PAÍS EN LA PRENSA COLOMBIANA

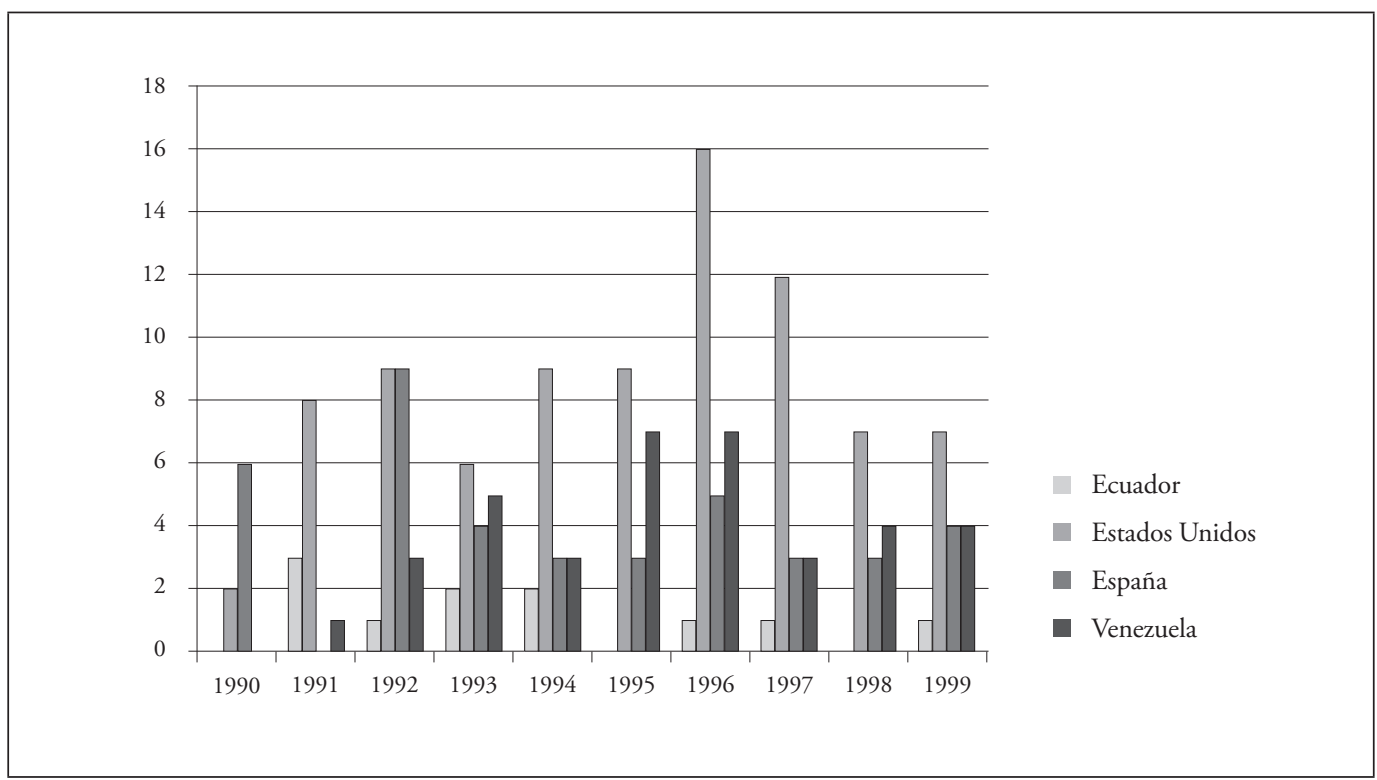

Fuente: elaboración propia a partir de los artículos extraídos de los periódicos El Espectador y El Tiempo, 1990-1999.

De los 173 artículos analizados correspondientes a este periodo, 40 hacen referencia a la comunidad colombiana en España, a diferencia de los 85 que serán consagrados a la migración colombiana hacia Estados Unidos. Esto puede explicarse, como lo mencionábamos ut supra, por el hecho de que es justamente este país, el que más migración colombiana registra, desde la época de los años setenta hasta la actualidad?

El análisis de los artículos permitió identificar las temáticas principales, que para efectos de este estudio denominaremos entradas, término prestado a la gramática. Los resultados de las entradas arrojan que las políticas migratorias son el segundo tema principal dentro de las diez primeras entradas en los periódicos colombianos. Esto haciendo referencia a todos los países en los que aparecen noticias relacionadas con los colombianos en materia de política migratoria, tal como lo indica la tabla 1.

9 Véanse los estudios realizados por Cardona (1980), NALEo y Fund and The Tomás Rivera Institut (1997); Collier y Gamarra (2001); Guarnizo (2008); Vicente et al. (2011). 
TABLA 1

TOTAL ENTRADA POLÍTICAS MIGRATORIAS EN LOS AÑOS NOVENTA EN LOS PERIÓDICOS COLOMBIANOS

\begin{tabular}{|l|c|c|c|c|c|c|c|c|c|c|c|}
\hline Resultado de entradas por año & 1990 & 1991 & 1992 & 1993 & 1994 & 1995 & 1996 & 1997 & 1998 & 1999 & Total \\
\hline Narcotráfico & 7 & 4 & 13 & 4 & 6 & 8 & 10 & 4 & 3 & 3 & 62 \\
\hline Políticas migratorias & 2 & 3 & 7 & 9 & 4 & 6 & 10 & 11 & 4 & 5 & 61 \\
\hline Colombianos en el exterior & 2 & 1 & 4 & 5 & 4 & 2 & 1 & 2 & 4 & 1 & 26 \\
\hline Identidad & & 1 & 3 & 1 & 1 & 3 & 3 & 1 & 3 & 4 & 20 \\
\hline Discriminación & & & 3 & 4 & 1 & 2 & 4 & 2 & 2 & 1 & 19 \\
\hline Sin papeles & & 3 & 1 & 2 & 1 & & 4 & 4 & 1 & 2 & 18 \\
\hline Delincuencia & & 1 & & 2 & 3 & 2 & 1 & 2 & 3 & 1 & 15 \\
\hline Migración y desarrollo & & 1 & 2 & & 2 & 1 & 2 & 3 & & 1 & 12 \\
\hline Diáspora & & & & 1 & & 1 & 1 & 1 & & 5 & 9 \\
\hline Remesas & & & & & & & & 1 & & & 1 \\
\hline
\end{tabular}

Fuente: elaboración propia a partir de los artículos extraídos de los periódicos El Espectador y El Tiempo, 199-1999.

Al detallar la información obtenida se pudo establecer-como se muestra en la tabla 2-que, en referencia a la migración hacia España, durante la década de los noventa las dos entradas que concentran el mayor número de men- ciones son las políticas migratorias y aquellas relacionadas con el narcotráfico, estableciendo así los temas recurrentes en el discurso que se va creando en la prensa de Colombia sobre la presencia colombiana en el extranjero.

TABLA 2

TOTAL DE ENTRADAS EN LOS AÑOS NOVENTA REFERENTES A ESPAÑA, EN LOS PERIÓDICOS COLOMBIANOS

\begin{tabular}{|l|c|c|c|c|c|c|c|c|c|c|c|}
\hline Entradas España & 1990 & 1991 & 1992 & 1993 & 1994 & 1995 & 1996 & 1997 & 1998 & 1999 & Total \\
\hline Narcotráfico & 5 & & 2 & 1 & 1 & & 3 & 3 & 1 & 16 \\
\hline Políticas migratorias & 1 & & 2 & & & 1 & 1 & & & 5 \\
\hline Identidad & & & 1 & & & 1 & & & & 1 & 3 \\
\hline Discriminación & & & 1 & & & & & & 1 & 1 & 3 \\
\hline Delincuencia & & & & 1 & & & & & & 1 & 2 \\
\hline Trata de personas & & & & & & & & & 1 & 1 & 2 \\
\hline Diáspora & & & & 1 & & & & & & & 1 \\
\hline
\end{tabular}

Fuente: elaboración propia a partir de los artículos extraídos de los periódicos El Espectador y El Tiempo, 1990-1999. 
Las cinco menciones que aparecen en la tabla 2, hacen referencia exclusivamente a las políticas migratorias en Espańa; sin embargo, para el análisis, hemos incluido artículos en los que se hace referencia a Europa de manera general, ya que permiten tener una visión de conjunto de lo que se expresa a este respecto en la prensa colombiana.

Como lo indican las tablas 1 y 2, las noticias sobre migración en general y sobre la migración hacia Espańa en particular, son reducidas en estos nueve años, hecho que nos lleva a concluir que la emigración de colombianos no es un tema prioritario en la prensa nacional de la época. Esto podría explicarse de dos maneras, una primera, desde el hecho de que la migración colombiana a Espańa empezará de manera continua a finales de la década, lo que de una parte explica su poca visibilidad y la presencia de países de tradición migratoria de los colombianos en los ańos setenta, como es el caso de Estados Unidos, Venezuela y Ecuador, donde ya existe una migración instalada (Guarnizo, 2003).

Esto puede igualmente entenderse desde el contexto mismo de conmoción en el que Colombia inicia los ańos noventa, sumergida en una gran ola de violencia generada por la guerra que declararon los carteles del narcotráfico al Gobierno colombiano durante la presidencia de Virgilio Barco Vargas (1986-1990), para evitar que la extradición hacia EE.UU. se pusiera en marcha (Santa María, 1998). En este ambiente se desarrollan las elecciones presidenciales de 1990, durante las cuales, tres de los candidatos fueron asesinados por orden de los narcotraficantes (p. 79) ${ }^{10}$. Resultado de estas, es electo el candidato liberal César Gaviria (1900-1994), gobierno durante el cual se declara la apertura económica en Colombia y se desarrollan distintos procesos de modernización del Estado y de negociación con las diferentes guerrillas. César Gaviria propone una amnistía general a los grupos guerrilleros, que concluye con la desmovilización del M-19, de una fracción del Ejército Popular de Liberación (EPL), del Movimiento Armado Quintín Lame (MAQL) y de algunas fracciones del Ejército de Liberación Nacional (ELN). Una de las condiciones para desmovilizarse será la Asamblea Nacional Constituyente de 1991, que pone en marcha este Gobierno, abriendo así las vías democráticas para la promulgación de la nueva Constitución colombiana y para la inserción política de dichos grupos armados. Sin embargo, las negociaciones instauradas con las guerrillas del ELN y con las Fuerzas Armadas Revolucionarias de Colombia - Ejército del Pueblo (FARC-EP), no condujeron a acuerdos concretos de paz, que pueden de una u otra forma explicarse por los antecedentes de las negociaciones precedentes -lo sucedido con los miembros de la Unión Patriótica-, por la caída del bloque soviético y por la declaración del presidente Gaviria de la "guerra abierta” contra la insurgencia en Colombia (Gonzales, 2003).

Este proceso político y de reforma institucional, va de la mano con la apertura

10 Entre ellos, Carlos Pizarro, Luis Carlos Galán Sarmiento, Bernardo Jaramillo Ossa. 
económica global, que dejará como saldo, muchas empresas del Estado privatizadas. De esta manera, el proyecto de democratización del país fue el de "implantar una economía de mercado haciendo parecer como que democracia y mercado son términos equivalentes en un país que carece de mercados desarrollados" (Álvarez, 2003, p. 134). "Durante estos años, hubo una tendencia a la revaluación del peso, creando serias dificultades para los exportadores legales y complicando más todavía la situación de los productores nacionales frente a la competencia de bienes importados" (Bushnell, 2007, p. 404).

Es en estas circunstancias, y después de la muerte de Pablo Escobar (1993) y del desmantelamiento del cartel de Medellín, que el candidato liberal, Ernesto Samper (19941998), llega a la presidencia de Colombia. Un periodo ambientado por las acusaciones en su contra, sobre la posible presencia de dinero del cartel de Cali en su campaña. Este hecho le valió las investigaciones de la Fiscalía General, que dieron como resultado la apertura de lo que se conoció como el "proceso 8000", que implicaba a hombres políticos y altos mandos del Gobierno con miembros del cartel de Cali.

Esta situación generó una crisis de institucionalidad, y una tensión particular con el gobierno de Estados Unidos, que descertificó a Colombia, tras considerar que no hacia esfuerzos suficientes para combatir al narcotráfico, e igualmente por la corrupción y los nexos del Gobierno con este, anuló la visa del presidente colombiano. Hasta el final de su mandato, y a pesar de haber sido declarado inocente después de su juicio ante la Cámara de Representantes, el escándalo siguió vigente y muchos de sus colaboradores, entre ellos Fernando Botero, ministro de Defensa, y Santiago Medina, el tesorero de la campańa, fueron condenados por corrupción y nexos con el narcotráfico ${ }^{11}$.

La crisis económica que se anunciaba debido al cambio del modelo impuesto por la apertura, genera un periodo de recesión económica; ante ello se vive una fuerte presión obrera de los sindicatos del sector eléctrico, de la Caja Agraria, del gremio de transporte, así como un gran paro armado campesino apoyado por la guerrilla de las FARC, que se opuso a negociar con el Gobierno por considerarlo ilegítimo y débil. De esta manera, se declara el estado de conmoción interior y de emergencia económico-social, debido al déficit fiscal $y$ a los constantes enfrentamientos entre las guerrillas y los paramilitares en el país, y, por consiguiente, el desplazamiento de personas que esto conlleva (Santos y Ramírez, citados en Tirado, 1998, pp. 157-191).

El siglo xx terminó con la más profunda crisis económica que ha experimentado Colombia. Para 1999, se registró un crecimiento negativo, por primera vez desde la Segunda Guerra Mundial. El país vivió una recesión económica general, con un aumento del desempleo, cuya tasa llegó prácticamente al $20 \%$ (Bushnell, 2007, p. 407). La crisis incluye sectores como el inmobiliario, en el que los precios

11 Esta descertificación dejaba a Colombia en el ostracismo diplomático, al lado de países como Afganistán, Siria, Nigeria e Irán (Santos, citado en Tirado, 1998, pp. 161-174). 
de la propiedad se desplomaron por debajo de las deudas de los propietarios, metiendo en crisis igualmente al sistema nacional de crédito inmobiliario; la quiebra de los bancos; el desplazamiento de la fuerza de trabajo hacia la informalidad, que para la época representaba el $60 \%$, así como la degradación del mercado de trabajo y el debilitamiento de las organizaciones que atienden la salud, las pensiones, la educación y el bienestar de los trabajadores (Kalmanovitz, 2007, pp. 580-584). De esta manera, se agravaba la "de por sí grave desigualdad económica, fuera como un fenómeno transitorio o como una característica intrínseca de la nueva política” (Bushnell, 2007, p. 408).

Es en este contexto de adversidad económica y social que se desarrolla la presidencia del conservador Andrés Pastrana (1998-2002), elegido presidente, bajo la promesa de resolver el conflicto armado colombiano por la vía del diálogo. Para tal fin, se instalan las mesas de negociación, aunque las negociaciones con el ELN fueron limitadas debido a los inconvenientes encontrados para determinar la zona de negociaciones. El 14 de octubre de 1998, se creó por decreto la Zona de distensión ${ }^{12}$, en la que estaba previsto realizar las negociaciones con la guerrilla de las FARC en el departamento del Caquetá y se define con ello los puntos comunes para la negociación Después de casi tres años de negociaciones con algunos periodos de cese al fuego, el proceso se anula dando paso a una degradación del conflicto armado debida a los enfrentamientos que se desencadenaron entre el Ejército y la guerrilla ${ }^{13}$. Estas condiciones de inestabilidad, no solamente política, sino también económica y social, servirán como factores de expulsión, para los colombianos que desde finales de la década empezarán un gran éxodo hacia el exterior, en busca de mejores condiciones de vida.

Es justamente en medio de este contexto, tanto nacional como de integración internacional, que las políticas migratorias toman toda su dimensión. Según el análisis de los resultados que arrojaron los periódicos colombianos, el tema se percibe desde un sentimiento de desequilibrio e inequidad, entre la política aplicada por España, la integración de los países europeos, y el discurso de la integración hispanoamericana. En este sentido, el foco de los periódicos colombianos a principios de la década se centra en el tema de la xenofobia en Europa, relacionándola con las políticas migratorias que se han decidido desde los acuerdos de Schengen. Un ejemplo de ello, El artículo de El Espectador (1990), titulado "Xenofobia comunitaria, Europa para los europeos". Con él se marca el inicio del primer periodo de desequilibrio e inequidad, a través de la descripción del proceso de integración de los países europeos, insistiendo en que "solo se reconocen los derechos de los inmigrantes siempre y cuando sean de la Comunidad Económica Europea”,

12 Esta zona desmilitarizada, comprendía los municipios de Mesetas, La Uribe, La Macarena, Villahermosa y San Vicente del Caguán.

13 Para más detalles sobre lo que han sido los procesos de negociación entre el Gobierno colombiano y la guerrilla, véase Gonzales (2003). 
subrayando así el carácter excluyente de la libre circulación al interior de las fronteras con respecto a los ciudadanos extracomunitarios. Para ilustrar este postulado, el corresponsal de El Espectador cita particularmente dos ejemplos, el de una persona de Egipto inmigrante en España y el de un líder sindical negro de Sudáfrica, invitado a dar una conferencia en España. A través de los malos tratos en España de los que han sido víctimas, concluye que se trata de una Europa cerrada que, con las leyes, propicia la xenofobia creciente en los diferentes Estados que la conforman, de ahí el título que da a su artículo.

De manera específica, cataloga de contrasentido dicha medida especialmente en el caso de países como España, "pues mientras tiene casi un millón de emigrantes en [su territorio] y más de medio millón en el resto de Europa, en su mayoría refugiados aceptados por los países durante la guerra civil española, los inmigrantes de todo el mundo en este país no alcanzan a los 400.000 en total" (El Espectador, 1990). Es importante anotar que para mediados de los años noventa, se contabilizaba de manera oficial la existencia de 2,1 millones de emigrantes españoles en el exterior (el 37\% en Europa y el $60 \%$ en América) (Actis et al., 1999, p. 62), hecho este que puede explicar lo incomprensible que resulta el surgimiento de brotes de xenofobia en un país de emigrantes.

El periodista se sitúa en la posición de observador de la realidad de los inmigrantes de otras nacionalidades, y la relación que puede existir entre los casos de xenofobia y las políticas que se desprenden de los acuerdos de
Schengen, centrando su análisis en lo que sucede particularmente en España. A pesar de que el artículo no hace referencia a la presencia de colombianos en dicho país, muestra la expectativa que van generando los acuerdos europeos.

A esta visión radicalizada de lo que serían las consecuencias de los tratados de Schengen, se suma una segunda reflexión a partir de las publicaciones que aparecen desde 1992, en torno a la integración iberoamericana paralela a la integración europea. Recordamos que nos encontramos en la época de la integración iberoamericana, que había comenzado un año antes con la I Cumbre Iberoamericana que tuvo lugar en México. Las celebraciones del V Centenario, fomentan la relación entre América Latina y España, de la misma forma que se desarrolla la capacidad de cooperación de esta con la zona, cuyo fin es el de potenciar las relaciones transatlánticas. Esto sin dejar de lado, que ya desde la década de los ochenta, los países de la región fueron declarados receptores prioritarios de la ayuda y cooperación española (Rodríguez, 2006, pp. 142-143). Hecho este que explica en cierto modo la actitud hacia la integración Europea y la inquietud que surge en los gobiernos latinoamericanos frente a los acuerdos del Tratado de la Unión Europea firmado en Maastricht en febrero del mismo año, que incluían medidas importantes en materia de inmigración.

"Acaban visa para ingresar a España" ( $E l$ Espectador, 1992). A través del titular de este artículo, se puede inferir que los colombianos necesitaban visa para entrar a España; sin embargo, de lo que se trata es de la reunión que 
se llevó a cabo entre los ministros de relaciones exteriores de España, Francisco Fernández Ordóñez ${ }^{14}$, y de Colombia, Noemí Sanín Rubio ${ }^{15}$, al final de la cual se especifica que si bien los colombianos no necesitan visa para entrar a España, y no la necesitarán una vez en marcha la disolución de las fronteras en Europa, sí deben cumplir con el requisito de 50 dólares al día durante su estancia y la confirmación en el tiquete aéreo de la fecha de regreso. Empero, se subraya la preocupación de las autoridades colombianas ante "el alto número de ciudadanos que están siendo devueltos de España desde el mismo aeropuerto" (El Espectador, 1992), principalmente por no cumplir con los requisitos de solvencia económica o no tener la documentación requerida.

Las declaraciones en relación con el visado, se presentan como una forma de tranquilizar a la opinión pública y aclarar las posibles dudas ante las nuevas medidas previstas por el Acuerdo de Schengen y el tránsito de los colombianos en España. Dicho encuentro se revela igualmente importante, ya que se desarrolló en Madrid en el marco de la integración iberoamericana, con el propósito de anunciar la firma del Tratado de Amistad y Cooperación entre Espańa y Colombia, a través del cual se pretende "ordenar las relaciones entre ambos países en áreas como la educación, el comercio y la cooperación judicial" (El Espectador, 1992). Este acuerdo forma parte de la reactivación de las relaciones entre Colombia y España, tal como lo citábamos anteriormente. De esta manera, El Espectador insiste en el hecho diplomático de los acuerdos, y en la no obligatoriedad de visado a los colombianos, sin dejar de subrayar la existencia de ciertas condiciones para el acceso.

En este mismo ańo, y a manera de ejemplo de lo que será la percepción entre América Latina, Espańa y la integración europea ${ }^{16}$, en

14 Ministro de Asuntos Exteriores (1985-1992) durante el Gobierno de Felipe González. Es justamente junto a él y a Fernando Morán, ministro de Exteriores (1982-1985) que queda fijado el nuevo sistema exterior español. Política adecuada a los problemas y escenarios decisivos de España, como la integración a Europa, a la OTAN, las relaciones especiales con Marruecos, la cooperación con América Latina y la relación equilibrada con Estados Unidos (García et al., 2008, p. 149).

15 Ministra de Relaciones Exteriores durante el Gobierno de César Gaviria (199-1994). Primera mujer en Colombia en estar a cargo del Ministerio de Relaciones Exteriores y una de las figuras más populares en ese momento (Santos, citado en Tirado, 1998, p. 165).

16 Esta integración fue seguida de cerca por los periódicos colombianos, particularmente el debate que esto generó en Francia, al momento del Referéndum para aceptar o no la ratificación del tratado sobre la Unión Europea. Muestra de ello son los artículos “O Maastricht, o Maastricht” (El Espectador 20/09/1992), el día del voto de los franceses. Un amplio análisis sobre el por qué sí, abanderado por el gobierno del socialista François Mitterand y representado por la figura del secretario del Partido Socialista de la época Laurent Fabius, y los defensores del no, representados en la foto que figura en el artículo, por Jean-Marie Le Pen, presidente del Frente Nacional. El segundo artículo, publicado una vez aprobado el Tratado por el voto francés, "Maastricht Sí, Maastricht No" (El Espectador, 1992), una entrevista a Alain Lipietz, en ese entonces director del Centro Nacional de Investigaciones Científicas de Francia y hoy día diputado europeo por el partido francés Europe Ecologie. Les Verts, sobre el porqué de su oposición frente al Tratado, que considera "como la puerta al dumping social y ecológico, además de verlo como el detonante en una decena de ańos 
materia de política migratoria en la época, $E l$ Tiempo (1992), en su artículo titulado "Del muro de Berlín al muro del sur", realiza una síntesis sobre el encuentro "Europa y América Latina. Recíproca percepción”, llevado a cabo en el marco del Foro sobre Democracia y Siglo xxI en Iberoamérica, realizado en la ciudad de Bogotá y organizado por la Fundación Santillana. La lectura que se desprende de los representantes latinoamericanos presentes en este encuentro, sobre la reorganización mundial y el comercio, se encuentra poblada de metáforas muy connotadas como la del muro de Berlín. La imagen del muro sugiere un sentimiento de desequilibrio e inequidad con respecto a la región, desde el punto de vista económico, y una impresión de rechazo hacia los latinoamericanos, por las consecuencias que la unificación europea y su política migratoria tendrán. Estas dos percepciones irán de la mano en los diferentes artículos encontrados a lo largo de 1992 y en el publicado en El Espectador (1995), "Nace una mini Europa sin fronteras".

Las declaraciones del excanciller argentino Dante Caputo, dan origen al título del artículo: "Del muro de Berlín al muro del Sur". Su tesis consiste en presentar la existencia de un muro que como el de Berlín, con las mismas connotaciones, separa la humanidad en dos bandos:

De un lado, los países desarrollados. Su inmensa riqueza económica y bienestar social. Del otro, las na- ciones pobres del Sur, de donde salen miles y miles de personas en busca de una vida más digna. Y en medio, las inmensas contradicciones: el trato a los inmigrantes en los aeropuertos europeos y norteamericanos, el racismo, el neonazismo, la xenofobia y el crimen $(E l$ Tiempo, 1992).

Según estas declaraciones, existen dos percepciones con respecto a la relación AméricaEuropa que plantea el encuentro. Una desde la posición de los excancilleres latinoamericanos, y, la segunda, desde la respuesta que dan los miembros del Gobierno español, que en este caso aparecen como representantes de Europa. Por parte de los excancilleres latinoamericanos, se exigen "reglas de comercio más flexibles" para frenar "el problema del sur", y con respecto a la migración, se espera de Europa y Estados Unidos, y más concretamente de España, respeto y mejor trato a los inmigrantes latinoamericanos que a sus ojos son vistos como "un problema de Estado, como si se viniera una gran invasión y fuese necesario adoptar una política de seguridad nacional" (El Tiempo, 1992). Esta visión se presenta como una amalgama entre la migración y la delincuencia por parte de las políticas asumidas por la CEE, se consideran como un aliento a los actos de xenofobia ${ }^{17}$ que han sucedido en Europa y que han sido registrados por la prensa colombiana desde 1990. Cuatro ejemplos, entre 1990 y 1992, ilustran este postulado: "Xenofobia comunitaria. Europa para los europeos" (El Espectador, 1990); "La

de "una guerra civil europea" cuando las dificultades económicas y sociales según los países, se deban a Maastricht y quieran dejar la Unión. O aún el artículo titulado "A visar antes de ir" (El Espectador, 1992).

17 Cfr. a este respecto los estudios de Bade (2002); Naïr y De Lucas (1996). 
plaga xenófoba asusta España” (El Espectador, 1992); "La xenofobia en Europa" (El Espectador, 1992); "Alarma en Espańa por crimen de xenófobos" (El Tiempo, 1992).

De estos artículos, dos hablan sobre Europa en general y dos específicamente de España. En el primer caso, Europa se evoca una vez más desde un lenguaje de referencia a la Guerra Fría, en el que se presenta a los inmigrantes como los nuevos enemigos europeos. "Los sentimientos que se volcaban contra los agentes del comunismo ruso, se hallan sin oficio y de esa manera tienen como blanco de sus iras a los argelinos, los turcos, los nativos de Afganistán, los albaneses, los latinoamericanos, la gente pobre que busca empleo" (Alfredo Vázquez Carrizosa, 1992).

Los tres artículos publicados en el mes de noviembre de 1992 hacen referencia a España, bien sea de manera directa: "Alarma en Espańa por crimen de xenófobos" (El Tiempo, 1992); "La plaga xenófoba asusta Espańa” (El Espectador, 1992), o para situarla en el contexto europeo en referencia al tema de la xenofobia: "La xenofobia en Europa” (El Espectador, 1992), partiendo, como punto común, del asesinato, a manos de jóvenes pertenecientes a una organización de tendencia nazi, de Lucrecia Pérez, inmigrante dominicana que se encontraba en Aravaca (Madrid) desde hacía dos meses. Este sería el primer crimen xenófobo de la historia de España, razón por la cual se creó un amplio debate social sobre las posturas más radicales de la xenofobia y el racismo, acompańado de un amplio seguimiento mediático (Retis, 2008, pp. 222-223).

La noticia se presenta como un acto que no es común en España y se refleja a través de verbos como "asustar" o "alarmar", que reenvían a una cuestión inesperada que genera preocupación, en este caso en la sociedad española, no acostumbrada a este tipo de situaciones. Los dos artículos describen la reacción general de la población civil española que respondió ante lo sucedido con una marcha de protesta de unas 3.000 personas ( $E l$ Tiempo, 1992; El Espectador, 1992) en contra de este tipo de actos, así como la reacción de diferentes actores políticos, entre ellos el vicepresidente del Gobierno español, Narcís Serra, quien "subrayó el empeño del [Gobierno español] en la lucha contra cualquier brote de racismo" (El Tiempo, 1992). En estos dos artículos se presenta el hecho como algo que no necesariamente obedece a una actitud general de la sociedad española frente a la migración, o aun frente a la comunidad latinoamericana. Cabe recordar que los estudios realizados en la época en España por el Centro de Investigaciones Sociológicas (CSI), demostraban que la población espańola rechazaba en un $83 \%$ las acciones llevadas a cabo por grupos xenófobos (cIs, 1993).

Si bien existen desde los años ochenta expresiones de racismo y de xenofobia en Europa, en casos como el de Francia y de Austria, estas manifestaciones se organizaron y encontraron ascenso político a través de grupos de extrema derecha. A diferencia de España, en donde este discurso, en la época, no contaba con un referente político o aun con representación parlamentaria (Actis et al., 1999, p. 168).

Siguiendo la línea del sentimiento de rechazo e inequidad que venimos exponiendo, se inscribe el artículo de El Espectador, "Nace 
una mini - Europa sin fronteras" (1995), con un lead ${ }^{18}$ en el que se lee: "Entra en vigencia la libre circulación de personas en 7 países. Extra europeos tienen limitaciones de visas, mientras América Latina no aplica el principio de reciprocidad". En este se habla de la evolución de los acuerdos europeos, del paso de la CEE a la UE que se consagra en el Tratado de Maastricht de 1992, describe el funcionamiento de la libre circulación prevista en el Acuerdo de Schengen y en qué afectará esto a los latinoamericanos y, más particularmente, a los colombianos.

A diferencia de los artículos anteriores, aquí se dedica una columna a la situación de los colombianos que lleva por título, "Candado a los colombianos", creando así la idea de encierro. La unificación de la visa europea implicaba que si un colombiano podía entrar en los países en los que no se le exigía visado -en la época: Alemania, España e Italia-, podía pasar noventa días en cada uno de ellos, con el acuerdo Schengen queda limitado a noventa días en total, por todo el territorio que se incluye en dicho tratado ${ }^{19}$.

El sentimiento de desigualdad se manifiesta a través del hecho de que para un colombiano se reduce el tiempo de estancia en un país europeo, mientras en Colombia un europeo que decide renovar su permiso de turismo puede hacerlo sin exigencia alguna de solvencia económica o domicilio. Frente a esto agrega que "el principio diplomático de la reciprocidad no es aplicado de la misma manera en Europa que en América Latina" (El Espectador, 1995), sugiriendo así, en pleno contexto de integración iberoamericana, que se podría pensar en una medida similar en América Latina, para equiparar lo que resulta de los acuerdos europeos en materia de libre circulación. El tema de la radicalización europea con respecto a la migración, se plantea desde el avance de la extrema derecha y los partidos frente-nacionales, y se acentúa al hablar del ministro del interior francés Charles Pasqua ${ }^{20}$, a quien presentan como abanderado "de una ideología matizada en contra de los extranjeros" (El Espectador, 1995), cada vez más presente en diferentes países de Europa. El artículo termina volviendo a la pregunta sobre el principio de reciprocidad, esta vez utilizando como ejemplo la apertura económica de América Latina, que califica de apertura sin control, frente a la política de la UE que, por el contrario, cierra sus fronteras.

Si partimos del encuentro "Europa y América Latina. Recíproca percepción”, que citábamos anteriormente, realizado en 1992, veremos que los cancilleres latinoamericanos coinciden en que "Hay una enorme disparidad

18 El lead es una parte de la estructura de un artículo de prensa a través del cual "se proporciona un resumen breve de los acontecimientos. [...] puede contener los resultados o consecuencias principales de las acciones y acontecimientos o reacciones (verbales) de los portavoces importantes" (van Dijk, 1983, p. 86).

19 Véase Acuerdo y Convenio de Schengen. Disponible en: http://europa.eu/legislation_summaries/glossary/schengen_agreement_es.htmeuropa.eu/legislation_summaries/glossary/schengen_agreement_es.htm

20 Charles Pasqua, ministro del Interior bajo la presidencia de François Mitterand, y el Gobierno de Édouard Balladur. La Ley Pasqua es la ley 93-1027 de agosto de 1993, relativa al control de la inmigración y a las condiciones de entrada, acogida y estancia de los extranjeros en Francia. Ley conocida por su carácter restrictivo de los flujos migratorios. 
entre el discurso del Quinto Centenario y la política que siguen las autoridades gubernamentales de España [concluyó el excanciller colombiano Ramírez Ocampo]. Hay que alterar sustantivamente las normas que se les aplican discriminatoriamente a quienes llegan a ese país" (El Tiempo, 1992). La disparidad, como vemos, está planteada desde la apertura que implican las relaciones económicas y los acuerdos que se establecen entre los diferentes países latinoamericanos y España, y las restricciones a la circulación de personas que se genera a través de las normas europeas. En este sentido, la idea de fortaleza que había sido aplicada a Europa, se aplica por extensión a España debido a las políticas en materia de migración que se derivan de los acuerdos europeos (Noya, 2009, p. 17). Aun teniendo en cuenta estos atenuantes, se espera de Espańa un trato preferencial con respecto a América Latina y se critica fuertemente el hecho de que un país como España, de tradición emigratoria hasta los años ochenta (Alted y Ansejo, 2006), rechace la entrada de inmigrantes en general y particularmente de inmigrantes latinoamericanos.

La percepción de España hacia América Latina y específicamente hacia Colombia, como resultado del encuentro, es expuesta por el excanciller español Fernando Morán ${ }^{21}$ y el secretario de Estado español para la cooperación internacional (1985-1988) y para Iberoamérica, Inocencio Arias. Para ellos no existe una "mentalidad popular antilatinoamericana", contrario a la visión de los representantes latinoamericanos. A pesar de que reconocen que "existe una connotación peyorativa en el término sudacas" que se utiliza para hacer referencia a los suramericanos en España, este también "tiene un significado cariñoso" (El Tiempo, 1992). En las declaraciones no se explican las razones que podrían justificar la utilización del término con un significado "cariñoso"; sin embargo, estudios como el realizado por Dolores Juliano en 1994, muestran que el empleo que se hace del término "sudaca" desde los años noventa, busca establecer una diferencia con respecto a los españoles, y al establecer la diferenciación entre el uno y el otro, poder determinar así, aquel que pertenece a la comunidad nacional, por consiguiente, es un término creado con objetivos de exclusión. ${ }^{22}$

La realidad de la inmigración en España se relativiza al hablar de las posibles causas que llevan a las personas a migrar a ese país, $\mathrm{y}$ por qué, según Inocencio Arias, en el caso de Latinoamérica se prefiere este a otros destinos:

21 Fernando Morán fue ministro de Asuntos Exteriores de Espańa (1982-1985) durante la primera legislatura del Gobierno socialista de Felipe González; después de sus gestiones para llegar al acuerdo que condujo a la anexión de España a la CEE, fue destituido de su cargo debido a su oposición a la permanencia de España en la OTAN (Soto, 2005, p. 253).

22 En España, el problema de la inclusión / exclusión es interesante en el caso de los latinoamericanos, dado que no presentan diferencias considerables (religiosas, de clases sociales, raciales, lingüísticas o educacionales) con la sociedad receptora. Al faltar los elementos a partir de los cuales se naturaliza la idea de exclusión, queda al descubierto la construcción social de los límites. El antecedente se encuentra en la conceptualización del “indiano” durante el siglo pasado, mediante el cual se "extranjerizaba" a nativos (Juliano, 1994, p. 23). 
El problema de la inmigración de latinoamericanos sí es relevante en España. Pero no solo de ellos. También de marroquíes. Hay un enorme desempleo en su país, pero la calidad de vida es superior y el trabajo es mejor pagado. Por eso, y el hecho de que el idioma no es una barrera para los latinos, España es una meta (El Tiempo, 1992).

Estas declaraciones dan a entender que la migración en 1992 es una cuestión de importancia en España. Sin embargo, si miramos las cifras que se avanzaban a mediados de la década, la población de origen extranjero solo alcanzaba el 1,2\% de la población (Vicente et al., 2011, p. 53). Esto quiere decir, que en el discurso del representante espańol, existe una idea sobrevalorada de la presencia extranjera en su país. Por otro lado, esta declaración pone en evidencia la responsabilidad de los países de origen en la decisión de los migrantes dado que, ante la falta de condiciones de vida y de trabajo, la opción de migrar se presenta como una solución, particularmente en el caso latinoamericano, en el que no existe barrera idiomática para insertarse en el mercado laboral espańol. El análisis continúa enfocándose en la situación de Colombia y España, particularmente en las medidas exigidas para la entrada de los colombianos, ante los diferentes casos de deportación que se registran en la prensa.

...hay un sobredimensionamiento $[. .$.$] en torno$ a un hecho concreto, el maltrato a colombianos en el aeropuerto de Madrid. Pueden ocurrir errores, pero es que la policía española también se equivoca. Un solo caso, dijo, puede opacar el común denominador. Y cita estadísticas: solo el 1,52 por ciento de los colombianos que llegaron a Madrid en 1991 fueron devueltos. De 32 mil colombianos, unos 450 no pudieron ingresar por falta de documentos o por no llenar los requisitos (El Tiempo, 1992).

La referencia no es solamente a declaraciones del Gobierno colombiano realizadas a principios de 1992, registradas en el periódico El Espectador (1992), sino también a un hecho en particular en el que se impide la entrada a España de 14 colombianos en el mes de agosto del mismo ańo. Las razones por las cuales se les devuelve, según el artículo "Impiden entrada de 14 colombianos a España” (El Espectador, 1992), se enmarcan en el empeño del Gobierno espańol por "combatir el tráfico de estupefacientes de Colombia hacia esa nación, el cual se ha incrementado últimamente". Una vez en Colombia, se confirmó que no había razones para expulsar las 14 personas, pues no existían antecedentes penales en ninguno de los casos. Ante esta situación, el excanciller español Fernando Morán insiste en que "no existe una política discriminatoria contra el colombiano. Por el contrario, lo que existe son unos acuerdos a nivel comunitario, que obligan a los Estados miembros, a tomar medidas respecto a la migración”. En este sentido, y según las declaraciones del mandatario español, es de recordar que los compromisos europeos en materia migratoria, implican un control severo de las fronteras exteriores, de las cuales Espańa es una de ellas. Desde esta perspectiva, la política migratoria se inclina 
hacia la garantía de un "espacio de seguridad $\mathrm{y}$ control de las fronteras exteriores y de lucha contra la delincuencia” ${ }^{23}$. En esta misma línea puede entenderse que, dentro de la protección de las fronteras, se encuentre igualmente el impedir la entrada de posibles narcotraficantes a España, más aún si tenemos en cuenta que en la época seguían presentes en el imaginario colectivo los efectos sociales que tuvo la "epidemia" del consumo de heroína que se vivió a lo largo de los años ochenta y principios de los noventa en Espańa, así como el aumento progresivo durante la década del consumo de cocaína (De la fuente et al., 2006, pp. 506-513) proveniente principalmente de Colombia. Sin embargo, a pesar de este enfoque dado, el hecho de que los colombianos hubieran sido expulsados bajo el argumento de sospecha de narcotráfico, sin elementos de juicio, pone de manifiesto que no se trata de un problema de cumplimiento de la normativa europea, sino de un acto abiertamente discriminatorio.

A partir de 1995, y hasta el año 2000, existe un vacío en los periódicos consultados en relación con las políticas migratorias en España, a excepción del artículo titulado "Visado para futuro... en pareja" de El Espectador (1996), a través del cual se da a conocer un fallo del Tribunal Superior de Justicia de Cataluña a favor de un colombiano, a quien "reconoció su derecho como homosexual que convive con un ciudadano espańol, a tener visado de residencia por reagrupamiento familiar". Fuera de este artículo, existe un silencio en relación con las políticas migratorias en España que es reemplazado en El Tiempo y El Espectador por un seguimiento de la evolución de las políticas migratorias en los diferentes países europeos: "Fuera patos" (ElTiempo, 1993); "Francia saca a la fuerza a los refugiados africanos" (El Espectador, 1996); "Francia fracasa con los ilegales" (El Espectador, 1996); "Francia reprimirá a la inmigración" (El Espectador, 1997); "Ley francesa de inmigración termina en enfrentamiento" (El Espectador, 1997); "Rebrote ultranacionalista en Francia” (El Espectador, 1997); "Inmigración camino al Senado" (El Espectador, 1997); "Las visas inglesas" (El Espectador, 1997); "Gran Bretańa refuerza control a los viajeros" (El Tiempo, 1998).

Los titulares aquí presentados muestran el interés particular de la prensa colombiana en la política francesa de control de la inmigración. Existe un seguimiento a la forma como se aprobaron y discutieron las leyes llamadas Pasqua (1986-1993) y Debré (1997), así como a las consecuencias que estas primeras causaron al crear lo que se conoce como los ni-ni, es decir, ni expulsables, ni regularizables ${ }^{24}$. El objetivo de la política migratoria francesa, en palabras de Sami Naïr, es el de "desestabilizar para ilegalizar, ilegalizar para excluir socialmente, $y$

23 Tratado de Maastricht, artículo 2. Disponible en: http://europa.eu/legislation_summaries/institutional_affairs/ treaties/treaties_maastricht_es.htm

24 En el capítulo titulado La crise algérienne de la nationalité française, Patrick Weil (2002) presenta el desarrollo de la política migratoria francesa, particularmente en lo concerniente a la adquisición de la nacionalidad. Explica de manera detallada el contexto histórico-político y las razones que motivan las reformas a la ley desde 1974, y cómo los migrantes pueden encontrarse en una sin salida administrativa, al no poder ser ni expulsados ni regularizados. 
excluir socialmente para expulsar fuera de las fronteras, [es decir] un verdadero giro xenófobo de la ley francesa" (Naïr y De Lucas, 1996, pp. 71-72). En este marco se sitúa igualmente la evacuación violenta, en 1996, de alrededor de 300 africanos que pedían su regularización al Gobierno francés, y que se encontraban en la iglesia de Saint Bernard en París ${ }^{25}$. Este hecho generó un fuerte movimiento de indignación frente al Gobierno y de solidaridad por parte de diferentes sectores sociales, cineastas, médicos, escritores e intelectuales, seguido de cerca por los medios de comunicación, no solamente franceses, sino también extranjeros, como fue el caso de la prensa colombiana.

\section{REFLEXIONES FINALES}

El tema de las políticas migratorias en los periódicos colombianos, se presenta a través del proceso de la integración europea y con él, las medidas que se toman a través de los diferentes acuerdos que la van configurando a lo largo de la década de los noventa. Este hecho toma toda su importancia, debido a que al mismo tiempo se desarrollan las estrategias para la integración iberoamericana y se espera de Espańa un compromiso al mismo nivel que el que va adquiriendo con Europa. Situación esta que, a la luz de las políticas migratorias restrictivas que se van aplicando con respecto a los ciudadanos de terceros países, resultan a los ojos de los políticos latinoamericanos, todo un contrasentido por parte de España.

Desde esta perspectiva, queda claro que la visión que prima es la de injusticia y desequilibrio, al considerar las diferencias en términos del derecho al desplazamiento que tienen los ciudadanos de la CE-UE con respecto a aquellos originarios de los terceros países. A partir de esta base se da la noción de Europa como fortaleza $y$, dentro de ella, la obligatoriedad en el cumplimiento de los acuerdos -en este caso los relacionados con la política de inmigración-, de la que deber hacer caso España por formar parte. Esta noción se relaciona con el hecho de que:

...las fronteras blindadas simbolizan siempre un cara a cara entre riqueza [o riqueza relativa] y pobreza. Indicios de desequilibrio económico y político [...]. No hay en esta estrategia [de instalación de fronteras y de muros], dos protagonistas identificados, sino un Estado de un lado [entendiendo aquí a la UE], y toda una población sospechosa del otro (Ritaine, 2009, p. 160).

Dejando así la impresión que se tendrá en materia de política migratoria en la época.

\footnotetext{
25 Situación que no era nueva, ya que en marzo del mismo año se había realizado un desalojo a la fuerza en la Iglesia de Saint Ambroise, de 294 africanos sin papeles, evacuados manu militari en París.
} 


\section{REFERENCIAS}

\section{Fuentes primarias}

\section{Prensa}

\section{Artículos analizados para este escrito}

Periódico El Tiempo, 1990-1999 (impreso y digital).

Periódico El Espectador 1990-1999 (impreso).

\section{Artículos citados en este escrito}

El Espectador (1990). Xenofobia comunitaria. Europa para los europeos.

El Espectador (1992). A visar antes ir.

El Espectador (1992). Acaban visa para ingresar a España.

El Espectador (1992). Impiden entrada de 14 colombianos a España.

El Espectador (1992). La plaga xenófoba asusta España.

El Espectador (1992). La xenofobia en Europa.

El Espectador (1992). Tratado por el voto francés, Maastricht Si, Maastricht No.

El Espectador (1995). Nace una mini-Europa sin fronteras. El Espectador (1996). Francia fracasa con los ilegales.

El Espectador (1996). Francia saca a la fuerza a los refugiados africanos.

El Espectador (1996). Visado para futuro... en pareja.

El Espectador (1997). Francia reprimirá a la inmigración.

El Espectador (1997). Inmigración camino al Senado.

El Espectador (1997). Las visas inglesas.

El Espectador (1997). Ley francesa de inmigración termina en enfrentamiento.

El Espectador (1997). Rebrote ultranacioanlista en Francia.

El Tiempo (1992). Alarma en España por crimen de xenófobos.
El Tiempo (1992). Del muro de Berlín al muro del sur. El Tiempo (1992). Europa y América Latina. Recíproca percepción.

El Tiempo (1993). Fuera patos.

El Tiempo (1998). Gran Bretaña refuerza control a los viajeros.

Vázquez Carrizosa, A. (1992). La xenofobia en Europa. El Espectador.

\section{Legislación}

Jefatura de Estado (1995). Tratado general de cooperación y amistad entre el Reino de España y la República de Colombia. Boletín Oficial del Estado (вов) núm. 182. Recuperado de https://www.boe.es/ diario_boe/txt.php?id=BOE-A-1995-18484

Cortes Generales (1978). Constitución Española 1978. Boletín Oficial del Estado (вов) núm. 311. Recuperado de http://noticias.juridicas.com/base_datos/Admin/constitucion.html.

Consejo de Tampere (1999). Recuperado de http://www. europarl.europa.eu/summits/tam_es.htm.

Schengen Acuerdo y Convenio (1985). Recuperado de http://europa.eu/legislation_summaries/glossary/ schengen_agreement_es.htm

Tratado de Maastricht. Recuperado de http://eur-lex. europa.eu/legal-content/ES/TXT/PDF/?uri=O J:C:1992:191:FULL\&from=ES

La Ley Pasqua: Ley 93-1027 de agosto de 1993. Recuperado de http://legifrance.gouv.fr/affichTexte.do?c idTexte=JORFTEXT000000530357

\section{Fuentes secundarias}

Alted, A., Asenjo, A. (coords.) (2006). De la España que migra a la España que acoge. Madrid: Fundación Francisco Largo Caballero Obra social de Caja Duero. 
Álvarez Zárate, J. M. (2003). El interés nacional en Colombia. Bogotá: Universidad Externado de Colombia.

Arbeláez, A. (1977). El éxodo de los colombianos en el periodo 1963-1973. Boletín mensual de estadistica, Xxvi (310). Bogotá: Dirección General de Información Técnica, DANE.

Actis, W., De Prada, M. Á., Pereda, C. (1999). Inmigrantes, trabajadores, ciudadanos: una visión de las migraciones desde España. Valencia: Universitat de Valencia, Patronat Sud-Nord.

Berramdane, A. (2009). L'émergence d'une politique européenne commune d'immigration et son externalisation progressive. En Abdelkhaleq, B. y Rosseto, J. (dirs.). La politique européenne d'immigration. Paris: Karthala.

Bade, K. (2002). L'Europe en mouvement : La migration de la fin du XVIII siècle à nos jours. Paris : Éditions du Seuils.

Bushnell, D. (2007). Colombia, una nación a pesar de sí misma. Bogotá: Planeta.

Cardona, R. (coord.) (1980). Eléxodo de colombianos: un estudio de la corriente migratoria a los Estados Unidos y un intento para propiciar el retorno. Bogotá: Ediciones Tercer Mundo.

Centro de Investigaciones Sociológicas (cIs) (1993). Actitudes ante la inmigración. Recuperado de http://www.analisis.cis.es/cisdb.jsp

Collier, M. y Gamarra, E. (2001). The Colombian diaspora in South Florida (Working paper núm.1). LACC, Working Papers Series, Paper 4. Recuperado de http://digitalcommons.fiu.edu/laccwps/4

De La Riva, I. (1992). Las cumbres Iberoamericanas. Política Exterior, 6 (28), 168-187. Recuperado de http://www.jstor.org/stable/20643293

Del Arenal, C. (1992). La política Iberoamericana de los gobiernos socialistas, versión ampliada de la publicación "Balance de una década de política iberoamericana de España”. Madrid: Cedeal.
Del Arenal, C. (2011). La política exterior de España y relaciones con América Latina. Madrid: Fundación Carolina.

Delgado, L. (2003). La política latinoamericana de España en el siglo xx. Ayer, Asociación de Historia Contemporánea, Marcial Pons (49), 121-160.

De La Fuente, L., Brugal, T., Domingo, A., Bravo, M., Neira León, M. y Barrio, G. (2006). Más de treinta ańos de drogas ilegales en España: una amarga historia con algunos consejos para el futuro. Revista Española de Salud Pública, 80 (5), 505-520.

De Lucas, J. (2003). Inmigración o globalización: acerca de los presupuestos de una política de inmigración. Revista Electrónica de Derecho de la Universidad de la Rioja (REDUR) (1), 43-70. Recuperado de http://roderic.uv.es/handle/10550/2098

García Delgado, J. L., Fusi, J. P. y Sánchez Ron, J. M. (2008). España y Europa. En Fontana, J. y Villares, R. (dirs). Historia de España. Barcelona: Marcel Pons.

González, E. y Pulido, A. (2008). Las multinacionales españolas en Colombia. Cali: Fundación para la investigación y la cultura.

Gonzáles, F. E. (ed.) (2003). Violencia Politica en Colombia: "De la nación fragmentada a la construcción del Estado". Bogotá: Cinep.

Guarnizo, L. E. (2008). Londres Latina: La presencia colombiana en la capital británica. México: Universidad Autónoma de Zacatecas.

Guarnizo, L. E. (2004). El transnacionalismo de los inmigrantes: convergencias teóricas y evidencia empírica a partir de los estudios de los colombianos, dominicanos y salvadoreños en Estados Unidos. En Portes, A. (coord.). El desarrollo de América Latina. Neoliberalismo, clases sociales y transnacionalismo (pp. 170-197). Bogotá: ILSA, Colección En Clave Sur. 
Guarnizo, L. E. (2003). La migración transnacional colombiana: implicaciones teóricas, prácticas. En Memorias del Seminario sobre Migración Internacional colombiana y la conformación de sociedades transnacionales. Bogotá: Ministerio de Relaciones Exteriores.

Izquierdo, A. y Fernández, B. (2006). Panorama de la inmigración en España. En Alted, A. y Asenjo, A. (coords.). De la España que migra a la España que acoge. Madrid: Fundación Francisco Largo Caballero Obra social de Caja Duero.

Juliano, D. (1994), La construcción de la diferencia: los latinoamericanos. Revista de sociología (43), 23-32.

Kalmanovitz, S. (2007). Economía y Nación: una breve historia de Colombia. Bogotá: Norma.

Mármora, L. (1979). Labor Migration in Colombia. International Migration Review, 13 (3).

Naïr, S. y De Lucas, J. (1996). Le déplacement du monde, Immigrations et thématiques identitaires. Paris: Kimé.

Noya, J. (2009). La nueva imagen de España en América Latina. Madrid: Tecnos y Real Instituto El Cano.

National Association of Latino Elected and Appointed Officials Education Fund (NALEO) y The Tomás Rivera Institut (1997). Constructing the New York Area Hispanic Mosaic: A demographic portrait of Colombians and Dominicans in New York. USA: The NALEO Educational Fund and The Tomás Rivera Policy Institute.

Oxfam Intermon (2010). Las relaciones bilaterales entre España y Colombia: ¿dónde quedan los derechos humanos y el derecho internacional humanitario? Recuperado de http://www.oxfamintermon.org/ es/documentos/09/09/10/relaciones-bilateralesentre-espana-colombia

Ramiro, P., González, E. y Pulido, A. (2008). Las multinacionales españolas en Colombia. Cali: Fundación para la Investigación y la Cultura.
Ritaine, É. (2009). Des migrants face aux murs d'un monde-frontière. En Jaffrelot, C. y Lequesne, C. L'Enjeu mondial. Les migrations (pp. 157-176). Paris: Presse de la Fondation Nationale des Sciences Politiques.

Retis, J. (2008). Génesis y evolución de la latinoamericanización de Espańa: el rol de los medios de comunicación en la construcción de la realidad migratoria. En Bañón, A. y Fonieles, J. (eds.). Manual sobre comunicación e inmigración. Donostia: Gakoa.

Rodríguez, J. (2006). Las relaciones bilaterales Colombia-España. Economía y Desarrollo, 5 (1), 141-157.

Santa María, R. (1998). Aspectos políticos del gobierno de Barco (1986-1990). En Tirado Mejía, Á. (dir). Nueva Historia de Colombia: Historia politica desde 1986. Bogotá: Planeta.

Silva, M. y Gaviria, C. (1998). Los años del revolcón (1990-1994). En Tirado Mejía, Á. (dir). Nueva Historia de Colombia: Historia política desde 1986. Bogotá: Planeta.

Soto, Á. (2005). Transición y cambio en España 19751996. Madrid: Alianza Editorial.

Tirado Mejía, Á. (dir) (1998). Nueva Historia de Colombia: Historia politica desde 1986. Bogotá: Editorial Planeta.

van Dijk, T. (1983). Estructuras textuales de las noticias de prensa. Análisi Quaderns de comunnicació i cultura, 7/8, Març, Universitat Autonoma de Barcelona.

Vicente Torrado, T., Ruíz Balzola, A. y Unzueta Sesumaga, A. (2011). Remesas, género y desarrollo: las migraciones colombianas en el País Vasco. Bilbao: Bakeaz.

Urquidi, V. y Vega, G. (1991). Unas y otras integraciones. México: El Colegio de México, Fondo de Cultura Económica.

Weil, P. (2002). Qu'est-ce qu'un français? Histoire de la nationalité française depuis la révolution. Paris: Grasset. 